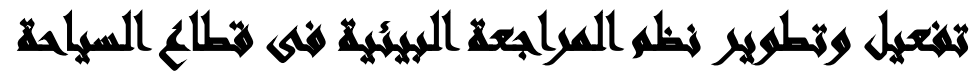

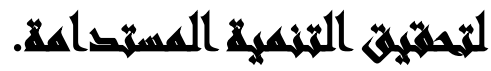

\section{$[r Y]$}

\author{
محمد محمود عبد المجيد (')- غادة عبد الله محمد (r)- كريم مصطفى(1) (ال) \\ فيفي محمود المرسى الثناوى (r)
}

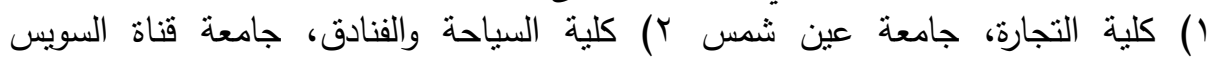

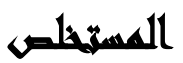

يهدف هذا البحث بصفة أساسية إلى توضيح دور المراجعة البيئية فى تحسين الأداء

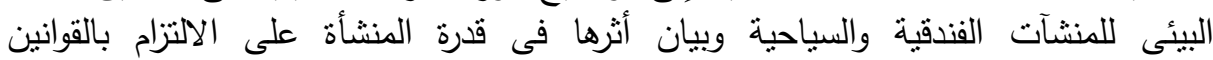

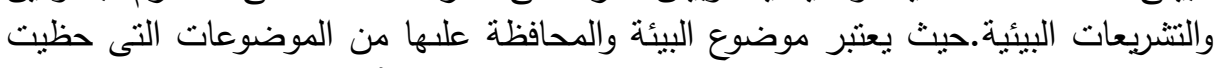

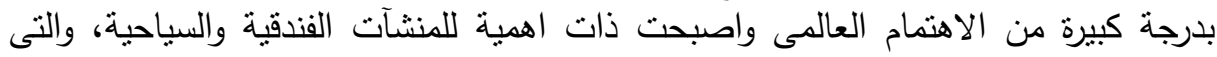

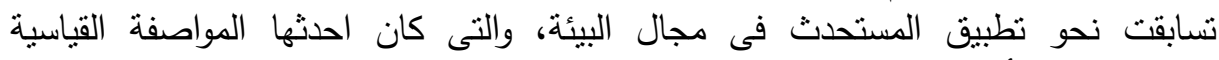

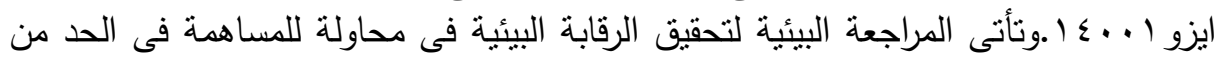

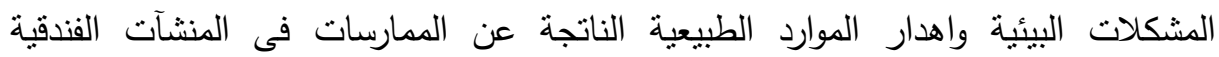

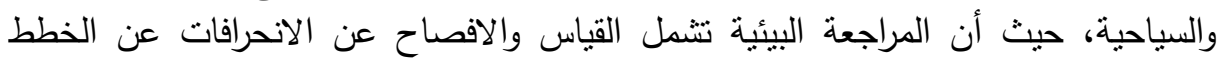

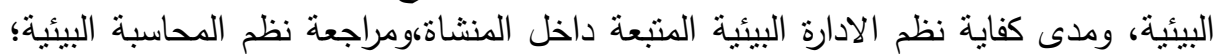

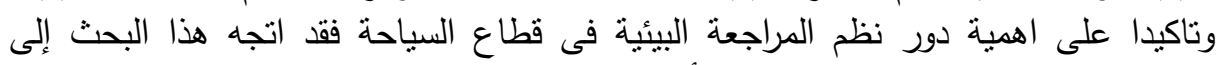

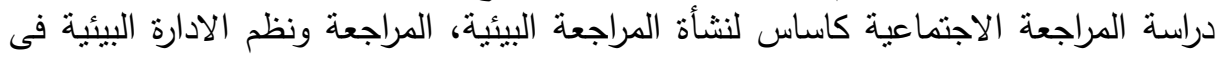

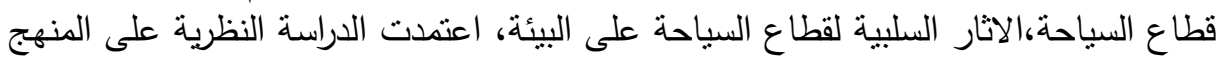

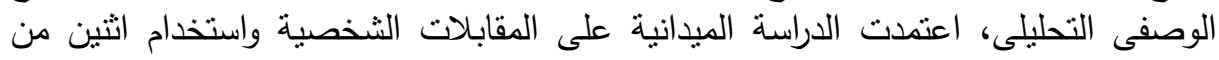

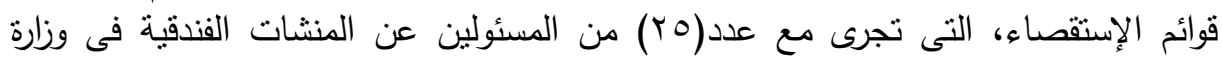

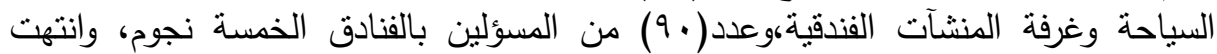

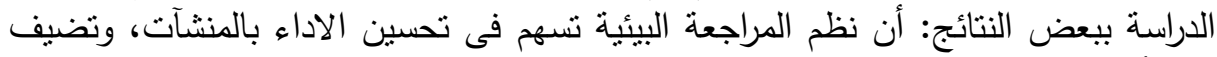

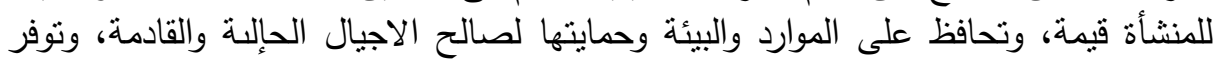
قاعدة بيانات خاصة وتؤكد على التزام المنثأة بالقوانين والتنشريعات البيأئية. 


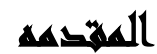

أدى ظهور جماعات الضغط البيئى والتى تهدف إلى حماية البيئة منل جماعات حماية البيئة وزيادة تأثثرها ومقاومتها للمنشآت التى تضر بالبيئة ومطالبتها بإيجاد الحلول اللازمة لذللك، أدى لتزايد الوعى البيئى فى جميع دول العالم إلى دفع منشآت الاعمال للتحرك بشتى بـى باليه

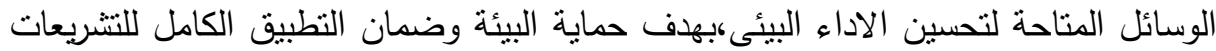
البيئية، والاعتماد على إلبات نوضح مدى اهتمامها بحماية البيئة خاصة فى القطاع السياحى وتهدف إلى الحفاظ على التتمية السياحية المستدامة،(• Diana,-Mihaelar ) ومن هذه الآليات المراجعة البيئية وفى ظل هذا المناخ اصبح الزاما على القطاع السياحى ان تتضمن التقاربر المالية إلى جانب نتائج الأداء الاقتصادى للمنشاة نتائج أخرى عن الأداء البيئى لها. ونظرا لطبيعة صناعة السياحة كنشاط اقتصادى مركب ومتداخل مع كثير من الأنشطة الآخرى، فقد ظهرت مشكلات أساسية تواجه السياحة أو تتعلق بالنشاط السباحى ولها تاثير ملهر

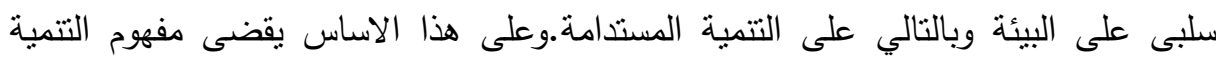

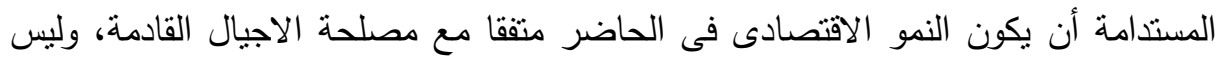

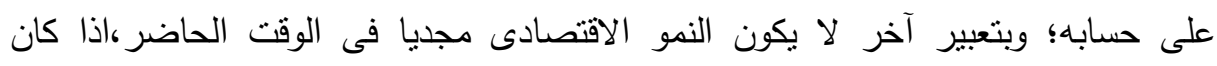

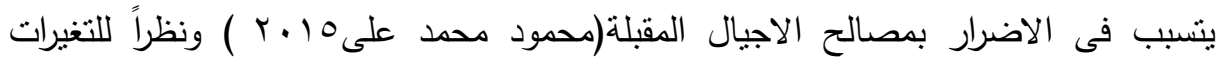
الجوهرية التى حدثت فى بيئة الأعمال، وزيادة الاهتمام بالبيئة والعمل على حمايتها وتلتميتها، وتحقيق ما يعرف بالتتمية المستدامة وتبنى المنشآت لفلسفيات واستراتيجيات جديدة مثل الجودة ولئه الثاملة، والتحسين المستمر ، كل هذه التغيرات وغيرها فرضت على بلى المنشآت ضغوطن كثنات كثيرة لتطوير نظمها الفنية والإدارية والمحاسبية وهذا بدوره القى على الباحثين فى مجال المراجعة ولثين

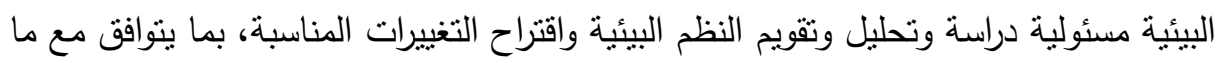




\section{مشفحلة التراسما}

على الرغم من تطبيق مصر لنظم الادارة البيئية فى بعض قطاعات الدولة منها القطاع السياحى (المنثآت الفندقية الحديثة) إلا ان مواردها تتعرض للاهدار الثنديد وتلوث البيئة طبقا

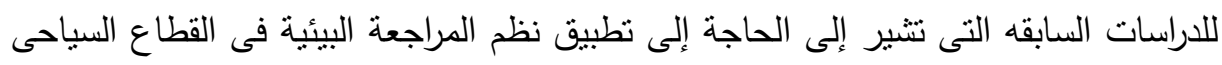

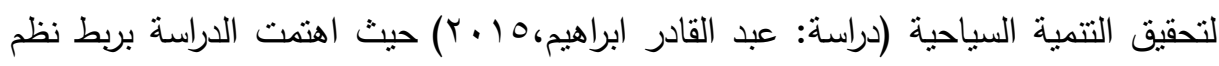
المراجعه البيئيه واطار التتميه المستدامه واكدت على اهمية المسؤليه الاجتماعيه فى دعم

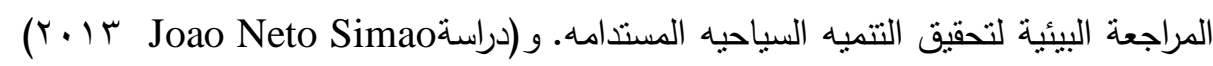
حيث أوصت الدراسة بعدم الاستخدام المفرط للموارد الطبيعيه والتى تشكل تهديداً واضحاً على

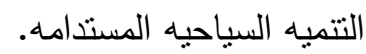

\section{أسركلة المهيه}

وتقف الباحثة على العديد من التساؤلات التى تتمثل فى مضمونها التساؤلات البحثية وأهمها: • ما القطاعات السياحية المختلفة التى تستخدم نظم الادارة البيئية وما نظم المراجعة البيئية

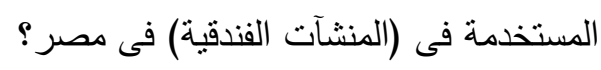

• هل تفى نظم المراجعة البيئية بإغراض توفير المعلومات اللازمة للرقابة، واتخاذ القرارات

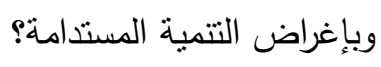

• هل هناك حاجة لتطبيق نظم المراجعة البيئية فى قطاع السياحة لتحقيق التتمية المستدامة؟ • هل يعتبر نطبيق نظم المراجعة البيئية افضل بديل يمكن استخدامة للحفاظ على البيئة

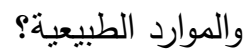

• هل هناك قصور فى نظم المراجعة البيئية المطبقة فى مصر؟

\section{أهمانهي التراسها}

ه التعرف على طبيعة انظمة المراجعة البيئية. • التعرف على ما هيه قطاعات السياحة التى تستخدم نظم الادارة البيئية. 
ثم. الوقوف على الانظمة المتعددة فى مجال المراجعة البيئية المطبقة فى المنشآت الفندقية.

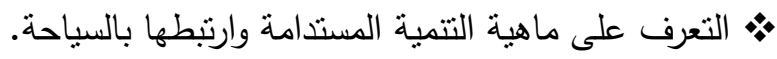
• ثطوير وتفعيل دور نظم المراجعة البيئية فى قطاع السياحة.

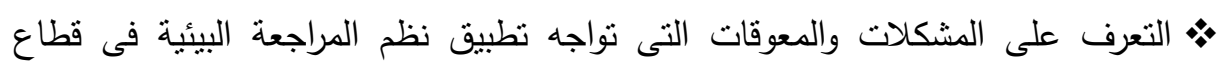
السياحة.

\section{أهمه التواسم}

تستمد الدراسة فى هذا البحث أهميتها من المساهمات العلمية التى تقدمها فى مجال

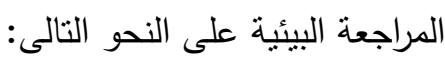

تعنبر هذه الدراسة مفيدة لقطاع السياحة فى التعرف على الاضافة الحقيقية لتطبيق نظم

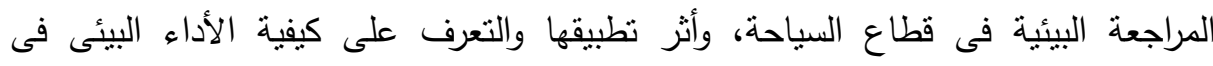

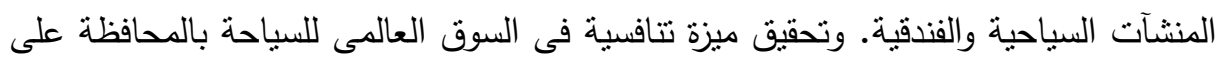
البيئة والموارد الطبيعية بهدف تتمية السياحية المستدامة فى مصر بتعتبر هذه الدراسة مفيدة فئه للعديد من الأطراف: الدولة: تعتبر الدراسة مفيدة للدولة حيث أنها نقوم بالحفاظ على البيئة والموارد الطبيعية،

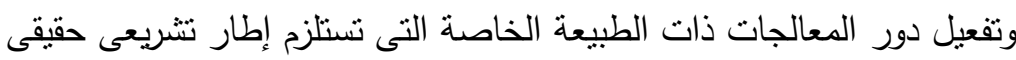

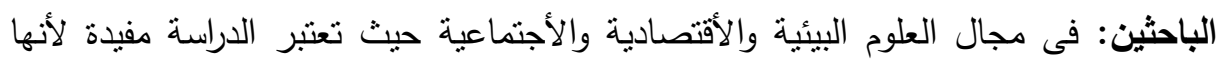

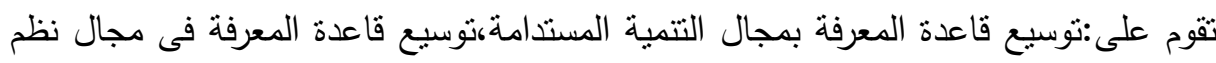
المراجعة البيئية، توسيع فاعدة المعرفة فى التشريعات الخاصة بالبيئة؛ الاطراف المستفيدة: الحفاظ على الاستمرارية وحق الأجيال القادمة، الحفاظ على السياحة لهاهية كونها مصدر هام من مصادر الدخل.تتمية السياحة من خلال الحفاظ على البيئة. 


\section{السراسايس المرجعية}

1-دراسة عبد القادر ابراهيم(0) ب ب): وهى بعنوان تعزيز مفهوم الممارسات الخضراء فى القطاع الفندقى لضمان التتمية السياحية المستدامة؛ وتهدف الدراسة إلى:زيادة الوعى بهى

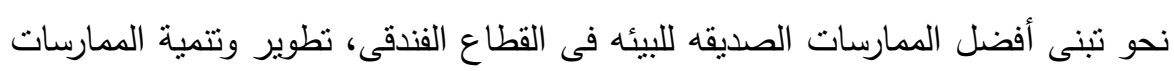

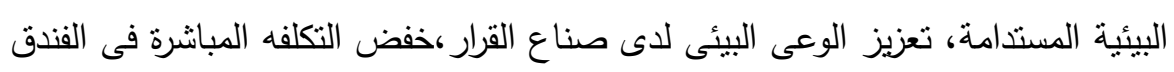

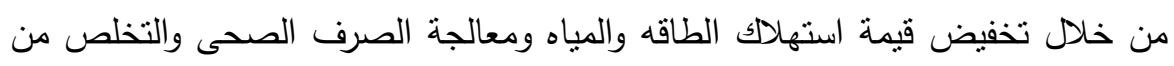

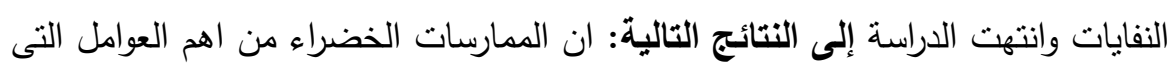
تساعد على تحقيق التتميه السياحيه المستدامه، قلة الوعى العام فى القضايا البيئية،

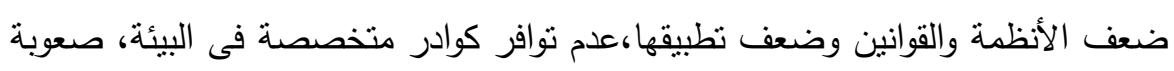
اجراء بعض التغيرات فى الفنادق القائمه، عدم نقل الخبرات من الدول المتقدمه، نطبيق

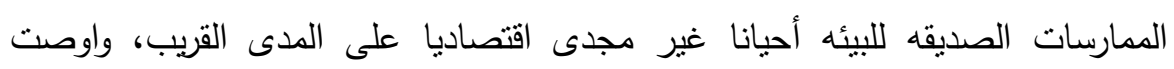

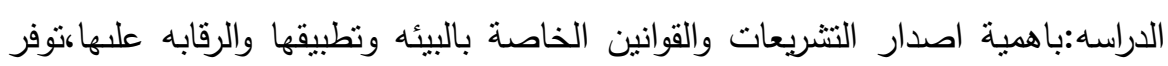

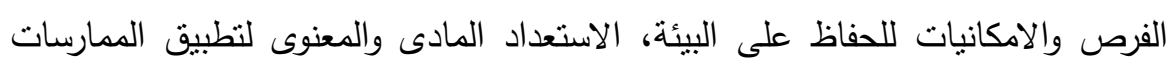

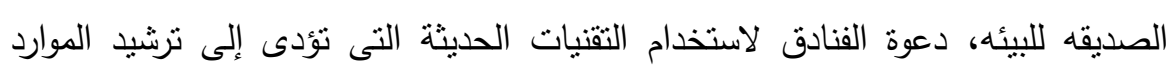

الطبيعية.

r- دراسة Georgiana Alexandru،(10) • ب): المراجعه البيئية ومتطلبات التتمية المستدامه؛ تهدف الدراسة إلى: تحقيق الوفاق بين البيئة والمجتمع والاقتصاد،

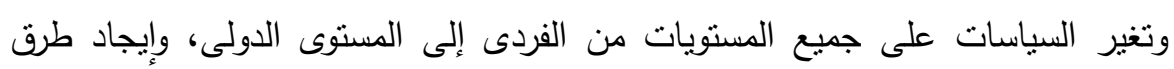

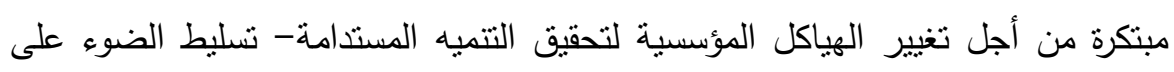

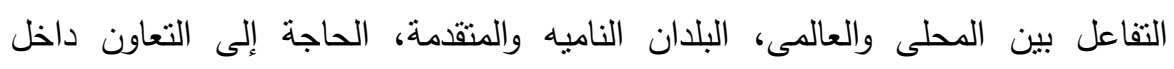
القطاعات وتوصلت الدراسه إلى: الاستخدام الاقتصادى للموارد،تتكيل سلوك واعى بالبيئه والامتتال لمبادئ التوجيهات البيئيه،الحد من استهلاك الكهرباء، وجود نظام الإداره البيئية

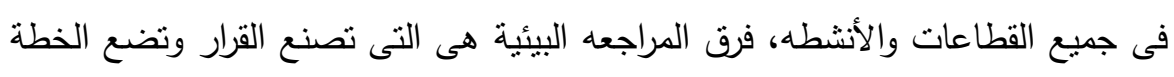
المستقبلية لتصل إلى نتيجة وحدة وهى الاستدامة. 


\section{هغوضر القواسمة}

الفرض الأول: لا يوجد ناثيرلنظم المراجعة البيئية على قطاع السياحة فى مصر • الفرض الثانى: لا توجد علاقة ذات دلالة أحصائية بين نظم المراجعة البيئية فى قطاع السياحة والتمية المستدامة. الفرض الثالث: لا يمنل تظوير وتفعيل نظم المراجعة أهمية خاصة فى قطاع السياحة فى الفرض الرابع: لا توجد علاقة بين نظم المراجعة البيئية وتحسين الاداء فى قطاع السياحة.

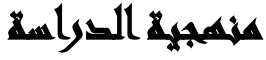

اعتمدت الدراسة النظرية على المنهج الوصفى التحليلى والمنهج الاستتباطى وذلك من خلال حصر وتحليل بعض الكتابات العلمية العربية والاجنبية والمرتبطة بجوانب التأصيل

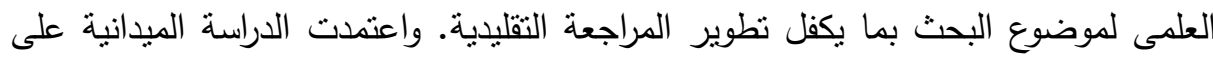
المقابلات الثخصية واستخدام قوائم الإستقصاء.

\section{مصوض القراسما}

- الحدود الزمنية: بدأ الباحثون بجمع البيانات اللازمة لاغراض الدراسة منذ عام ع ا ـ ؟. - الحدود المكاتية: تم القاء الضوء على بعض الممارسات البيئية داخل المنشآت الفندقية بالتطبيق على فنادق فئة الخمس نجوم بالقاهرة على اطراف المدينة.

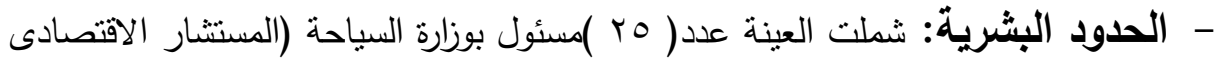
والبيئى لوزير السياحة، رئيس قطاع الفنادق بالوزارة، مديرعام الفنادق الثابتة، مديرعام الفنادق العائمة، مديرعام القرى السياحية مدير ادارة البيئة، مدير ادارة النجمة

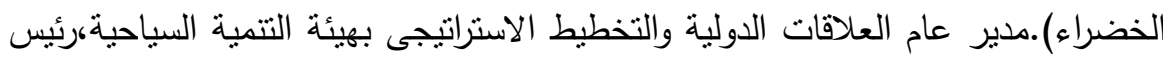
غرفة الفنادق،رئيس وحدة النجمة الخضراء بالغرفة . 
|ه شملت العينة عدد(V) مسئول فى الفنادق فئة الخمس نجوم ضمن اربعة مستويات ادارية من منصب مدير عام، نائب مدير ، كبير مهندسين، رئيس قسم، محاسبين، مهندسين.

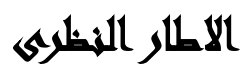

المراجعة الاجتماعية كأساس لنشأة المراجعة البيئية: مع بداية السبعينات حيث بدأ العديد من الباحثنن محاولات جادة لتقديم إطار علمى متكامل للمحاسبة والمراجعة؛ حيث قامت بعض الهيئات العلمية والمهنية فى الخارج بتكوين لجان خاصة لدراسة هذا الموضوع وتقديم

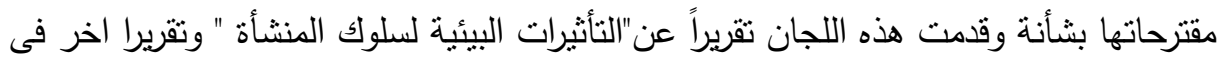

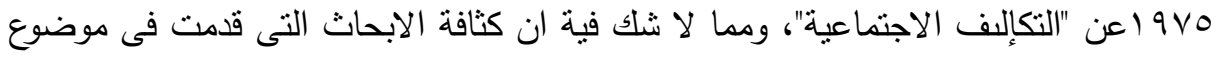
المحاسبة والمراجعة الاجتماعية خلال السبعينات وما قدمت من حلول عملية لمشكلة المحاسبة والمراجعة عن الاداء الاجتماعى للمنشأة، قد أثرت على كل من الفكر المحاسبى والتطبيق

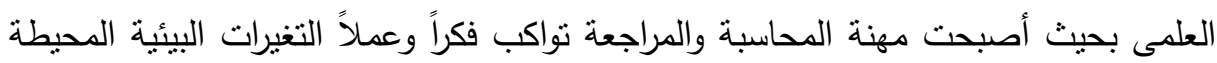

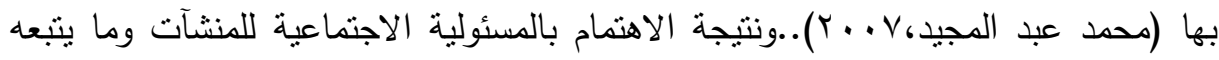

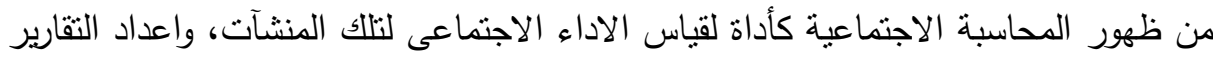
والقوائم الاجتماعية،نبعت الحاجة إلى ايجاد وسيلة للتحقق وتقييم ذلك الأداء بصورة مستقلة عن الاداء الاقتصادى للمنشآت،ولذلك تضافرت عديد من العوامل للمطالبة لايجاد مفهوم جديد للمراجعة تحكمة مجموعة من المعايير لغرض فحص وتقييم الجانب الاجتماعى لاداء المنشآت،وقد اطلق على ذلك المفهوم اصطلاح المراجعة الاجتماعية والتى يمكن تعريفها كالآتى:"فص وتقييم فنى منظم وحيادى للمعلومات المتعلقة بالأداء الاجتماعى للمنشآت والذى يكمن تمييزه عن النشاط الاقتصادى لها، بغرض التحقق من مدى صدق وعدالة تعبير

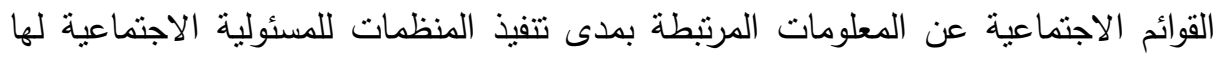

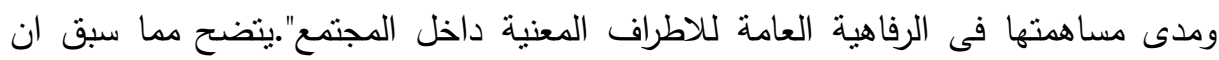
المراجعة الاجتماعية هى أساس نشأة المراجعة البيئية حيث انها نثأت عند تحديد اطار قياس 


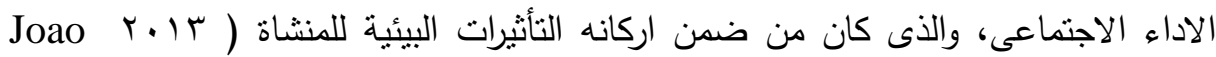

(Neto Simao

مفهوم المراجعة البيئية: "فحص انتقادى دورى منظم وموثوق وموضوعى بواسطة المنشأة او بواسطة جهة خارجية ذات سلطة قانونية للتعرف على مدى انسجام عمليات التشغيل والممارسات المختلفة مع المنطلبات القابلة للنطبيق وما يرتبط بها من انشطة لتحديد ناثيرها

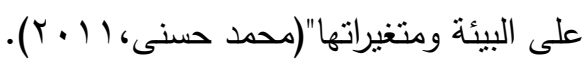

المراجعة ونظم الادارة البيئية فى قطاع السياحة: يقصد بنظم الادارة البيئية مجموعة من

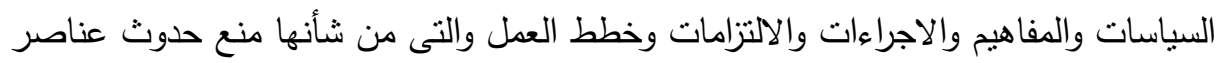

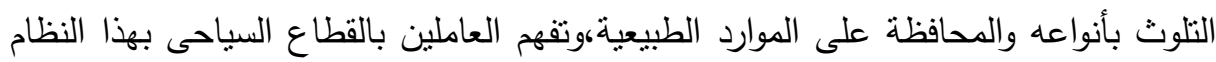

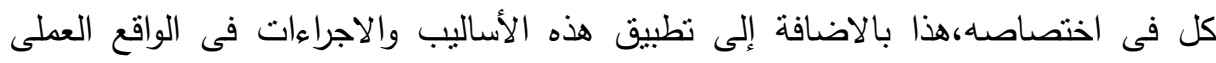

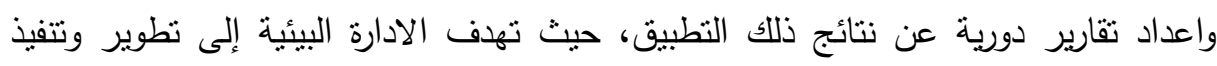
وادراة وتتسيق ورقابة انشطة القطاع السياحى بهدف تخفيض الأثار السلبية على البيئة

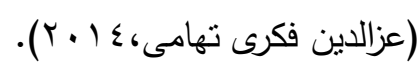

\section{بعض الاثار السلبية لقطاع السياحة على البيئة:}

- السياحة تؤدى إلى استهلاك كميات كبيرة من الموارد الطبيعية فهى نشاط يولد أيضا المخلفات سائلة وصلبة والتى اصبحت مشكلة بسبب عدم القدرة على معالجتها؛ فالنشاط السياحى يؤدى ايضا إلى تلوث المناطق الساحلية و الثؤاطىء الناجمة عن الفنادق والسفن وتتشير التقديرات إلى أن السفن السياحية فى البحر تتتج كميات من النفايات، كما ان

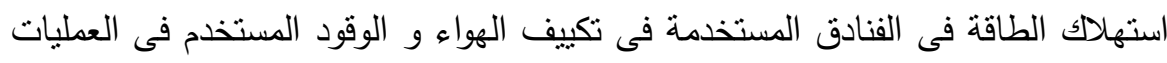
المرنبطة بالنشاط السياحى كالنقل، والتى تساهم بشكل كبير فى تلوث الهواء، وأيضا الفنادق العائمة التى تقوم بالصرف الصحى فى مياة النهر وتسريب الزيت والوقود مما

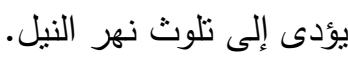


- ان مصادر المباة العذبة محدودة فى بعض المناطق ويتم استغلالها فى صناعة السياحة

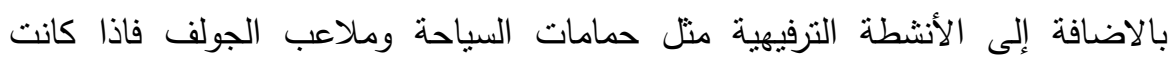
السياحة تؤدى إلى ندرة المياة فهى كذللك تؤدى إلى الافراط فى استغلال الموارد الطبيعية.

\section{السواسمة المهيدانهية}

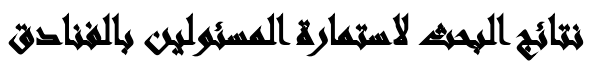

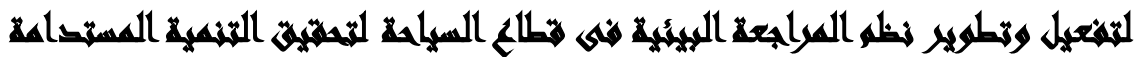

أولاً: طرق جمع البيانات: اعتمدت الباحثة على نوعين من البيانات:

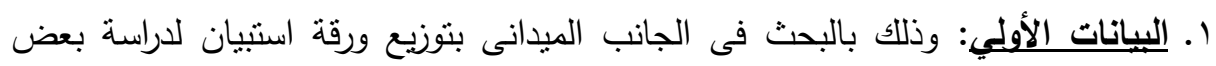

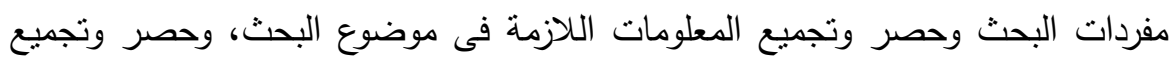
المعلومات اللازمة فى موضوع البحث، ومن ثم تقريغها وتحليلها باستخدام البرنامج الاحصائى Statisticl Package for Social Science) SPSS واستخدام المعالجات

الاحصائية المناسبة بهدف الوصول لدلالات قيمة،ومؤشرات تدعم موضوع الدراسة.

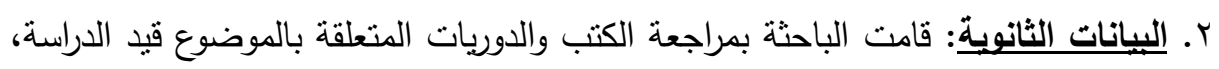
والتى تتعلق تفعيل وتطوير نظم المراجعة البيئية فى قطاع السياحة لتحقيق التتمية

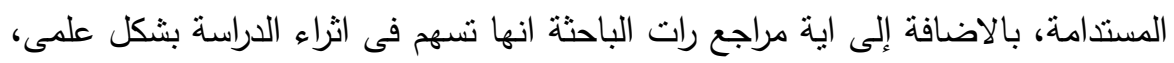

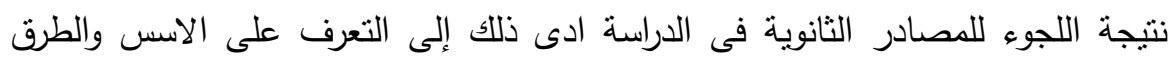

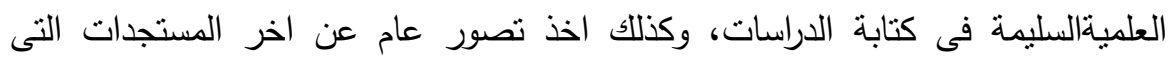
ظهرت ومازالت تظهر فى مجال الدراسة.

ثانياً: مجتمع وعينة الاراسة: اعتمدت الباحثه فى جمع البيانات من المسئولين فى في الفنادق على قائمة استقصاء، وتم اختيار هذه الفئة لاستطلاع ارائهم حول موضوع البحث، ومن

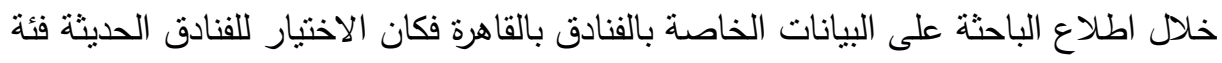

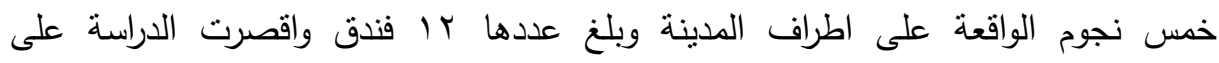


الوظائف الثاللة بالفنادق مديرالفندق ومساعد مدير، مدير نظم المعلومات، وكبير مهندسى ومهندسين ومحاسبين بالفندق وكان اجماإلى عدد العينة من العاملين بالفنادق • 9 مفردة. ثالثاً: التحليل الإحصائي: تم تفريغ البيانات عن طريق البرنامج الإحصائي المعروف بأن Statistical Package For Social برنامج الحزم الإحصائية للعلوم الاجتماعية Sciences الإحصائية SPS V. 20 وتعد هذه الخطوة - تفريخ البيانات- خطوة تمهيدية لتبويب

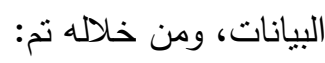

ا- اختبار الثبات من خلال معامل ألفا كرونباخ Alpha Cronbachs لاختبار ثبات الاستقصاء. r- اختبار صدق الإتساق الداخلي من خلال معامل إرتباط بيرسون بين الأبعاد وإجمالى الاستقصاء. r- الإحصاءات الوصفية للبيانات من خلال جدولة البيانات في صورة جداول نكرارية (التكرار والنسبة المئوية) لأسئلة استمارات الاستبيان. عـ ايجاد العلاقات الإرتباطية بمعامل ارتباط بيرسون لأبعاد فروض الإناسة. 
معادئة "هيريرت اركن"

9. ادخل حجم المجتمع N في الخلية المقابلة فيريلة اركن

\begin{tabular}{|c||cc}
\hline VY,qY & $=0.025510204$ \\
& $=0.00650771$ \\
\hline
\end{tabular}

$\mathbf{N}$

حجم المجتمع

$\mathbf{t}$

الدرجة المعيارية المقابلة لمستوى الدلالة 0.95 وتساوي 1.96

SE $\quad$ ن

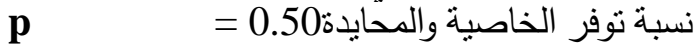

$$
n=\frac{p(1-p)}{(S E \div t)+[p(1-p) \div N]}
$$

تم تحديد حجم عينة الدراسة باستخدام معادلة "هيربرت اركن" السابقة حيث بلغ حجم المجتمع (•9) من العاملين بالفنادق المستهدفة للبحث، وتم حساب عينة الدراسة (VT) مفردة

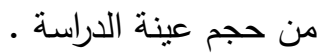

جدول رقم(1 ): حساب حجم عينة الدراسة

\begin{tabular}{|c|c|c|c|c|c|}
\hline المئويبة & الالصتبيانات & الاستتبياناتة & الالمتبيجانات & حجم عاينة & \\
\hline$\% \vee 々, 7$ & 0 . & 7. & $7 V$ & $7 \mathrm{~V}$ & استماررات الفنادق \\
\hline
\end{tabular}

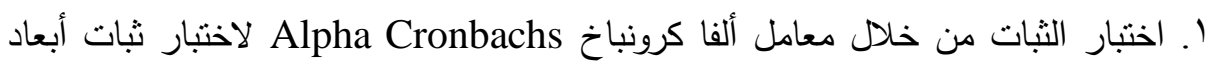

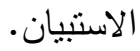

r. اختبار صدق الإتساق الداخلى من خلال معامل ارتباط بيرسون بين أبعاد الاستبيان وإجمإلى الاستبيان. 
اختبار صحة الفرض الأول: لا يوجد تاثير للمراجعة البيئية على قطاع السياحة فى مصر

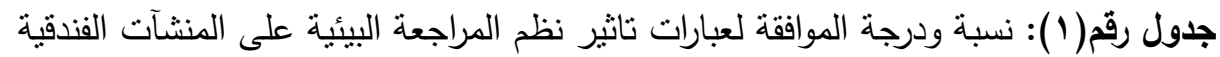

\begin{tabular}{|c|c|c|c|c|}
\hline الموجة & نافبة & الإنعياري & الأوسطابي & 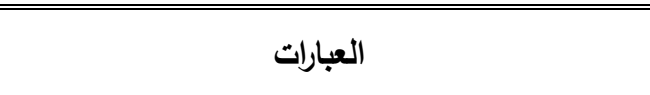 \\
\hline موافقة & $91,7$. & $\cdot, 71$ & $\varepsilon, 01$ & يتم التزام المنشأة الفندقية بتطبيق نظم الإدارة البيئية \\
\hline موافقة & $\wedge \wedge, \cdots$ & $\cdot, \mathrm{OV}$ & $\varepsilon, \varepsilon$. & البيئية. ممارسة اسلوب الادارة طبقا للقوانين والتشريعات \\
\hline موافقة & $\wedge \vee, \neg$. & $\cdot, \mathrm{TV}$ & $\varepsilon, \Gamma \wedge$ & يتم تتفيذ السياسات والالتزام البيئى فى ادارة الفندق. \\
\hline موافقة & $\wedge \varepsilon, \wedge$. & $\cdot, \lambda r$ & $\varepsilon, Y \varepsilon$ & يتم تقييم الأداء البيئي للمنشأة. \\
\hline موافقة & $\vee \vee, T$. & $\cdot, 9$ & 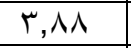 & يتم الإفصاح والقياس للتكاليف البيئية فى التقارير الدورية \\
\hline 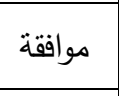 & $V Y, \varepsilon$. & $\cdot, \lambda)$ & r, & فيتم المنشأة الفندقية. الإدارة البيئية مع محاسبة التكإلف البيئية \\
\hline موافقة & $77, \varepsilon$. & $\cdot, \lambda \varepsilon$ & 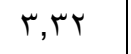 & يتم نشر البيانات البيئية فى التقارير المالية بالمنشاة. \\
\hline موافقة & $\vee \wedge, \varepsilon \cdot$ & $\cdot$, , & r, qr & يوجد قالعدة بيانات ملائمة لاستخدامها بشكل موسع فى البئية. \\
\hline موافقة & $\vee \cdot, \varepsilon \cdot$ & $\cdot, 91$ & r,or & يتم تدوير مخلفات بالمنشأة. \\
\hline موافقة & $\wedge 0, r$. & $\cdot, \wedge 0$ & $\varepsilon, Y \uparrow$ & بتم خفض المستخدم من الموارد من الماء والطاقة. \\
\hline موافقة & $7 \varepsilon, \varepsilon$. & $\cdot, 91$ & $r, Y r$ & يتم إستخدام الطاقة الثمسية. \\
\hline موافقة & $\wedge \neg, \uparrow \wedge$ & $0, .9$ & $\varepsilon r, r \varepsilon$ & إلاجمالى \\
\hline
\end{tabular}

• من الجدول السابق للتكرارات والنسب المئوية لعبارات ناثير نظم المراجعة البيئية على

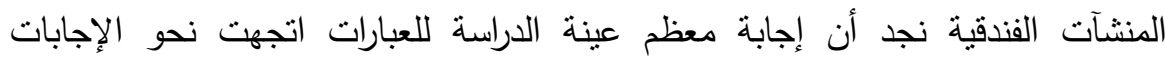

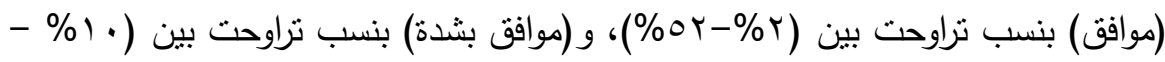

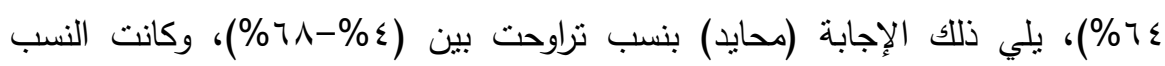
ضعيفة للإجابتين (غير موافق) و (غير موافق بشدة) كما بالجدول أعلاه.

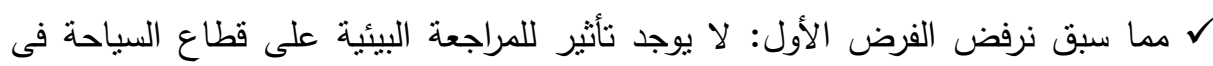
مصر. ل ونقبل الفرض البديل: بوجد نأثثر للمراجعة البيئية على قطاع السياحة فى مصر . 
إثبات صحة الفرض الثانى: لا توجد علاقة ذات دلالة إحصائية بين نظم المراجعة البيئية فى قطاع السياحة والتتمية المستدامة جدول رقم(Y): نسبة ودرجة الموافقة لعبارات تآثير المنشآت الفندقية على التتمية المستدامة

\begin{tabular}{|c|c|c|c|c|}
\hline الموافةة درة & نسبة المّة & الإنحراف & الإسطابط & العبارات \\
\hline موافقة & $\wedge \wedge, \wedge$. & $\cdot, V \cdot$ & $\varepsilon, \varepsilon \varepsilon$ & 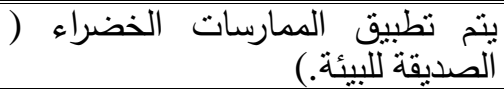 \\
\hline غير موافق & ro,7. & 1,11 & $1, \vee \wedge$ & ويؤثر الفندق سلبا على البيئة المحيطة \\
\hline موافقة & 10,7 . & $\cdot, \wedge r$ & $\varepsilon, r \wedge$ & الاجتيال الحفاظ علي البيئة وحمايتها لصالح \\
\hline موافقة & 09,7 . & $1,0 \mathrm{~V}$ & $r, q \wedge$ & الإباح السريعة للمستثرين الاهنمام بالتاثيرات البيئة التمية. \\
\hline غير موافق & $r_{0, r}$. & 1,10 & $1, \vee 7$ & استرايتذامية ليست ادارة المنشاة. عنصرا اساسيا فى \\
\hline غير موافق & r $\varepsilon, \varepsilon$. & $1, \cdot 1$ & $1, V Y$ & مصدرا رئيسيا للتلوث في البيئة. \\
\hline موافقة & $\Lambda T, \varepsilon$. & $1, \cdot r$ & $\varepsilon, 1 Y$ & البيولوجاظي. على الموارد الطبيعية والتتوع \\
\hline موافقة & $\Lambda \vee, 7$. & $\cdot, 9 r$ & $\varepsilon, \Gamma$ & تقوم المنشأة بتوفر الطاقة. \\
\hline غير موافق & 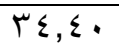 & $1,1 \wedge$ & $1, V Y$ & فقد كمبات كبيرة من المباة. \\
\hline محايد & $\leqslant 7, \cdots$ & $1, \Gamma$ & $r, r$ & لا تقوم المنشأة بتدوير المخلفات. \\
\hline موافقة & $09, \cdots$ & $0, \varepsilon$ & $r q, \Sigma \wedge$ & الإجمالى \\
\hline
\end{tabular}

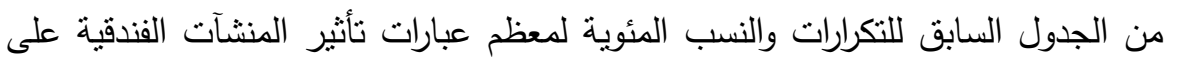
التتمية المستدامة عدا العبارتين (الاستدامة ليست عنصرا اساسيا فى استرايتجية ادارة

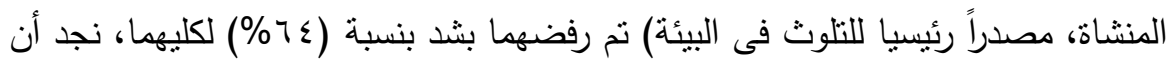

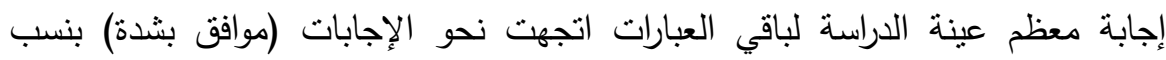

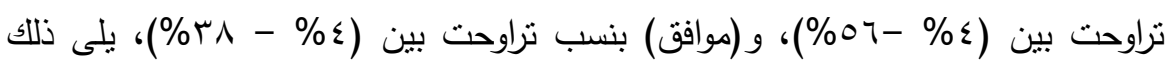

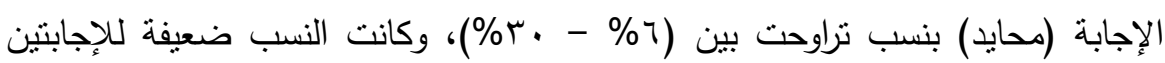
(غير موافق) و (غير موافق بشدة) كما بالجدول أعلاه. 
جدول رقم(ץ): نسبة ودرجة الموافقة لعبارات فوائد تطبيق نظم المراجعة البيئية فى المنشآت الفندقية

\begin{tabular}{|c|c|c|c|c|}
\hline لدرجةة & 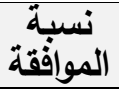 & الإنحراف & الحسبط الوسط & العبارات \\
\hline موافقة & $\Lambda \varepsilon$ & $1, Y$. & $\varepsilon, Y \cdot$ & خفض التكاليف \\
\hline موافقة & $\wedge \wedge, \wedge$ & $\cdot, \wedge I$ & $\varepsilon, \varepsilon \varepsilon$ & خفض المخاطر البيئية في المنشأة الفندقية. \\
\hline موافقة & 94 & $\cdot, 01$ & $\varepsilon, 7$ & تزيد من تميز المنشأة وقدرتها على التتافس. \\
\hline موافقة & Vᄉ, $\varepsilon$ & $\cdot, \wedge$. & $r, q r$ & زيادة اعداد السياح. \\
\hline موافقة & $9 r, \Lambda$ & $\cdot, 0 M$ & $\varepsilon, 7 \varepsilon$ & تحسين المظهر العام للمنشاة الفندقية. \\
\hline موافقة & $91, r$ & $\cdot, 7 \leq$ & $\varepsilon, 07$ & الاجيال الحإلـة والقادمة. على البيئة وحمايتها لصالح \\
\hline موافقة & 9 . & $\cdot, \wedge\urcorner$ & $\varepsilon, 0$. & الإدارة البيئية. للمراجعة الدورية والثاملة لنظام \\
\hline موافقة & 91,7 & $\cdot, 0 \leqslant$ & $\varepsilon, 0 \wedge$ & الانشطيز. على كافة الجوانب البيئية لجميع \\
\hline موافقة & $9 r, 1$ & $\cdot, 07$ & $\varepsilon, 7 \varepsilon$ & الاستخدام الامثل للموارد الطبيعية. \\
\hline موافقة & $\wedge 9,1$ & $\varepsilon, r_{0}$ & $\varepsilon \cdot, \cdot \Lambda$ & المنشآتي الفندقية تطبيق نظم المراجعة البيئية فى \\
\hline
\end{tabular}

من الجدول السابق للتكرارات والنسب المئوية لعبارات فوائد تطبيق نظم المراجعة البيئية فى المنشآت الفندقية نجد أن إجابة معظم عينة الدراسة للعبارات اتجهت نحو الإجابات (موافق لهاب

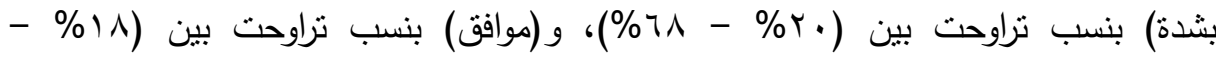

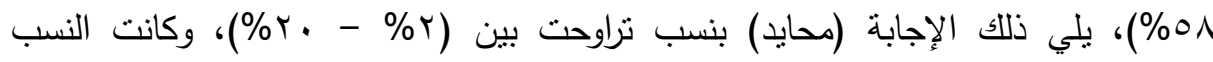
ضعيفة للإجابتين (غير موافق) و (غير موافق بشدة) كما بالجدول أعلاه. 
جدول رقم(؟): العلاقة الارتباطية بين نظم المراجعة البيئية فى قطاع السياحة والتتمية

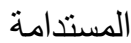

\begin{tabular}{|c|c|c|}
\hline التنمية المستدامة & & المتغيرات \\
\hline$\left("{ }^{\prime \prime \prime)},, \leq \leq 99\right.$ & معامل الارتباط & \multirow{2}{*}{ نظم المراجعة البيئية } \\
\hline$\cdot, \cdots 1$ & الدلالة المعنوية & \\
\hline
\end{tabular}

• من الجدول السابق ينضح وجود علاقة ارتباطية بين نظم المراجعة البيئية فى قطاع السياحة والتتمية المستدامة عند مستوى معنوية (0. . •) حيث بلغت قيمة الدلالة المعنوية

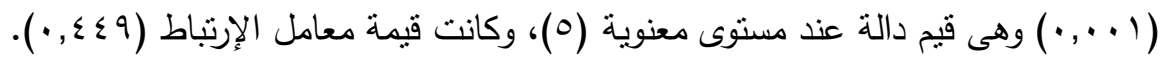
ل مما سبق نرفض الفرض الثانى: لا توجد علاقة ذات دلالة إحصائية بين نظم المراجعة البيئية فى قطاع السياحة والتتمية المستدامة. ل ونقبل الفرض البديل: نوجد علاقة ذات دلالة إحصائية بين نظم المراجعة البيئية فى قطاع ولئه السياحة والتتمية المستدامة.

إثبات صحة الفرض الثالث: لا يمثل تظوير وتفعيل نظم المراجعة أهمية خاصة فى قطاع السياحة فى مصر. جدول رقم(ه): هل يوجد قسم للمراجعة البيئية بالمنشأة؟

\begin{tabular}{|c|c|c|}
\hline النسبةة & العدد & الإجابة \\
\hline$V \varepsilon$ & rv & $y$ \\
\hline rq & $1 \pi$ & نعر \\
\hline $1 \ldots$ & 0 . & الاجمالى \\
\hline
\end{tabular}

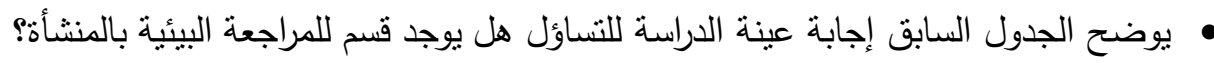

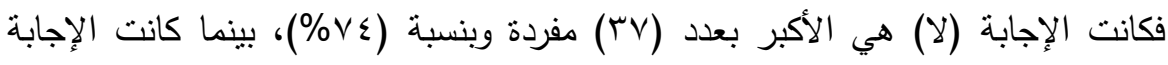

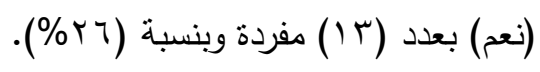


مجلة العلوم البيئية

معهد الدراسات والبحوث البيئية - جامعة عين شمس لينه

جدول رقم(†): نسبة ودرجة الموافقة لعبارات تفعيل نظم المراجعة البيئية بالمنشآت الفندقية

\begin{tabular}{|c|c|c|c|c|}
\hline الموافةة & الموافِة & الإنحراف & الحسطابى الوسط & العبارات \\
\hline 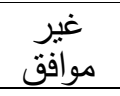 & $r r$ & 1,91 & 1,1 . & الممارسات ورابة قائشم الراجعة البيئة. الداخلية على \\
\hline 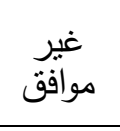 & $r \cdot, \Lambda$ & 1,91 & $1, \cdot \leq$ & 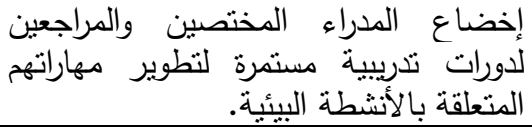 \\
\hline موافقٍ & 19,7 & $1, \wedge 1$ & $\cdot, 91$ & والندوات الزام المتعلقة بالمراجعة البيئية ـ المؤتنمرات \\
\hline موافيز & $r \cdot, \Lambda$ & 0,00 & r, & الفندقية تقييم نظم المراجعة البيئية بالمنشآت \\
\hline
\end{tabular}

• من الجدول السابق لنسبة ودرجة الموافقة لعبارات تفعيل نظم المراجعة البيئية بالمنشآت

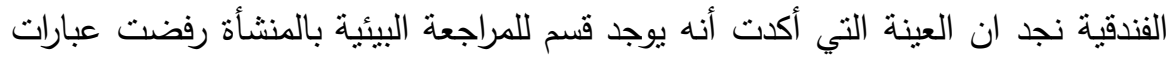

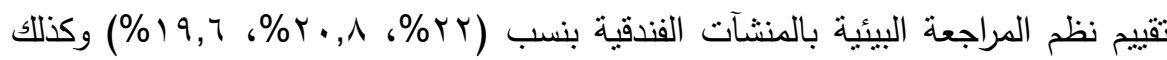
بالنسبة (لإجمالىى تقييم نظم المراجعة البيئية بالمنشآت الفندقية) كانت نسبة الموافقة (\%r., • مما يشير لرفض العينة للبعد. 
جدول رقم(V): نسبة ودرجة الموافقة لعبارات تطوير نظم المراجعة فى المنشآت الفندقية

\begin{tabular}{|c|c|c|c|c|}
\hline الموافقة & نسبة & الإلمعياري & الحسبطي & العبارات \\
\hline مواققة & $9 r$ & $\cdot, 7 \leq$ & $\varepsilon, 7$. & للتبينية. المنشأة الفندقية تطبيق المبادئ الصديقة \\
\hline موافقة & 17 & $\cdot, \vee 7$ & $\varepsilon, \Gamma$ & الفندقية. قاعدة بيانات خاصة بالبيئة بالمنشأة \\
\hline موافقة & $\wedge \varepsilon, \varepsilon$ & $1,1 \mathrm{~V}$ & $\varepsilon, Y Y$ & 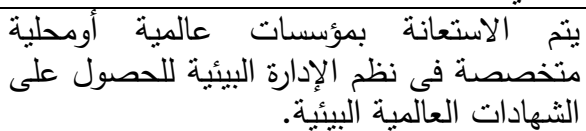 \\
\hline موافقة & $77, \varepsilon$ & $\cdot, \wedge \vee$ & rr, & التخ الاستعرانة البيئة بخبراء بيئيين لتقييم وفحص \\
\hline موافقة & $\Lambda \wedge, \varepsilon$ & $\cdot, V \cdot$ & $\varepsilon, \varepsilon Y$ & شهادات عالمية منل ( عصول المنشأة الفندقية على \\
\hline موافقة & $\wedge \wedge, \varepsilon$ & $\cdot, \vee \vee T$ & $\varepsilon, \varepsilon Y$ & 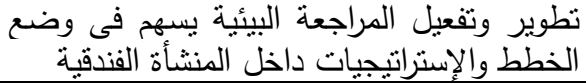 \\
\hline موافقة & 71 & $\cdot, \wedge 7$ & r, $\varepsilon$. & مرنييين من الثركات التابعة بيأية مشتركة مع اعضاء \\
\hline موافقة & $V Y$ & •, & r, & البيئية تقعيل وتطوير دور المراجع ليشمل المراجعة \\
\hline موافقة & $\Lambda \cdot, \varepsilon$ & $1, \cdot \varepsilon$ & $\varepsilon, \cdot r$ & المراجعة مبادئ ومعايير بيئية بعتمد علها لأداء \\
\hline موافقة & $\vee \varepsilon, \varepsilon$ & $\cdot, \wedge \neg$ & $r, V r$ & 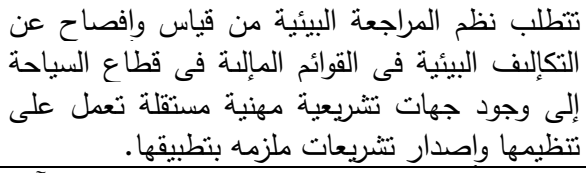 \\
\hline موافقة & $\Lambda$. & $\varepsilon, 07$ & $\varepsilon \cdot, \cdot r$ & إجمإلى تطوير نظم المراجعة فى المنشآت \\
\hline
\end{tabular}

- من الجدول السابق للتكرارات والنسب المئوية لعبارات نطوير نظم المراجعة البيئية

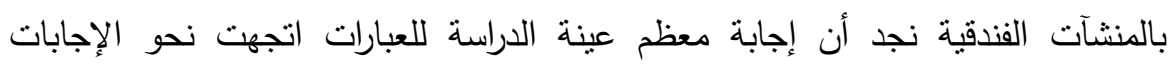

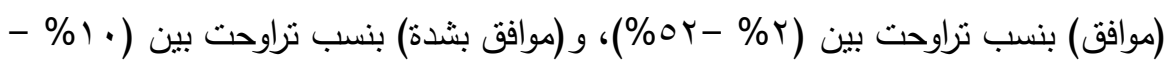

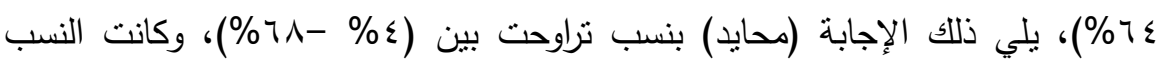
ضعيفة للإجابتين (غير موافق) و (غير موافق بشدة) كما بالجدول أعلاه. 
ل مما سبق نرفض الفرض الثالث: لا يمثل تطوير وتفعيل نظم المراجعة أهمية خاصة فى

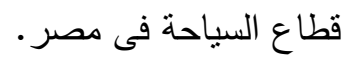
ل ونقبل الفرض البديل: يمثل نطوير وتفعيل نظم المراجعة أهمية خاصة فى قطاع السياحة إثبات صحة الفرض الرابع: لا توجد علاقة بين نظم المراجعة البيئية وتحسين الاداء فى قطاع السياحة. جدول رقم(^): نسبة ودرجة الموافقة لعبارات أسباب قصور نظم المراجعة البيئية بالمنشآت الفندقية

\begin{tabular}{|c|c|c|c|c|}
\hline الموأفقة & نسبة الموقة & الإنعصياري & الحسبابي الوسي & 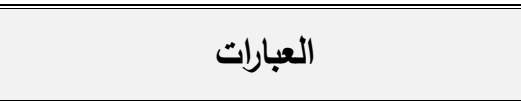 \\
\hline موافقة & 9. & $\cdot, \vee q$ & $\varepsilon, 0$. & بالمنشأة الفندقية. البيأى لدى المسئولين \\
\hline موافقة & $9 \cdot, 1$ & $\cdot, V_{1}$ & $\varepsilon, 0 \leqslant$ & ضلفعتية. نظم الإدارة البيئية فى المنشأة \\
\hline موافقة & $\wedge\urcorner, \varepsilon$ & $\cdot, \wedge \varepsilon$ & $\varepsilon, M$ & عدم وجود لوائح وضوابط بيئية. \\
\hline موافقة & $\wedge 9,7$ & $\cdot, \wedge 9$ & $\varepsilon, \Sigma \wedge$ & المراجعة البيئة. وتدريب المراجع فى مجال نظم \\
\hline موافقة & $\Lambda t$ & 1,0 & $\varepsilon, 1$. & اداء المراجعة الإهتمام بتطبيقة بالمنشاة الفندايية المهنية لتتظيم \\
\hline موافقة & $\wedge 9,7$ & $\cdot, \wedge !$ & $\varepsilon, \varepsilon \wedge$ & ضعف التقارير البيئية بالمنشأة الفندقية. \\
\hline موافقة & $\wedge \wedge, \varepsilon$ & $\cdot, \vee\urcorner$ & $\varepsilon, \varepsilon r$ & 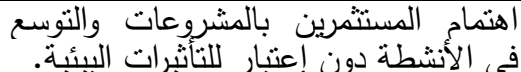 \\
\hline موافقة & $\wedge\rceil, \Sigma$ & $1, \cdot r$ & $\varepsilon, Y Y$ & ضعف تطبيث التشريعات البيئية. \\
\hline موافقة & $\Lambda \Lambda, \Sigma$ & $\cdot, 91$ & $\varepsilon, \Sigma Y$ & بحضور الزام الندوات في مجين بال الييئة . \\
\hline موافقة & $V \varepsilon$ & $1, r q$ & $r, \mathrm{~V}$ & 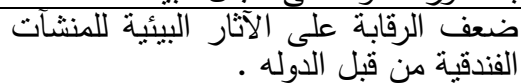 \\
\hline موافقة & $\wedge\urcorner, \varepsilon$ & $\cdot, 7 \wedge$ & $\varepsilon, \Gamma$ & 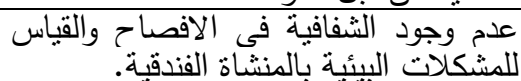 \\
\hline موافقة & $9 \cdot, 5$ & $\cdot, 70$ & $\varepsilon, O Y$ & ضعف دور المراجع بالمنشاة الفندقية . \\
\hline موافقة & $9 \cdot, \varepsilon$ & $\cdot, \wedge 7$ & $\varepsilon, 0 Y$ & عدم الاهتمام بالبيئة في التخطيط . \\
\hline موافقة & $9 \cdot, \varepsilon$ & $\cdot, \vee \vee$ & $\varepsilon, O Y$ & عدم الاهتمام بالبيئة في اتخاذ التقرارات \\
\hline موافقة & 70,7 & $1,0 \wedge$ & r, rᄉ & 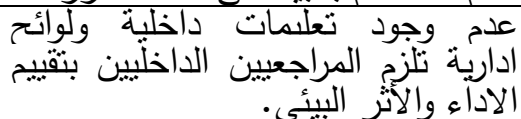 \\
\hline موافقة & 10,9 & $\vee, \wedge \leq$ & $7 \varepsilon, \varepsilon \varepsilon$ & 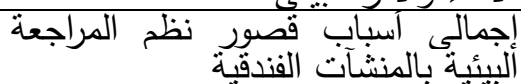 \\
\hline
\end{tabular}


من الجدول السابق للتكرارات والنسب المئوية لعبارات أسباب قصور نظم المراجعة البيئية بالمنشآت الفندقية نجد أن إجابة معظم عينة الدراسة للعبارات اتجهت نحو الإجابات (موافق

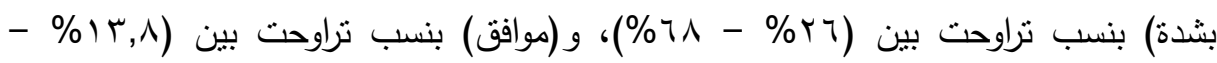

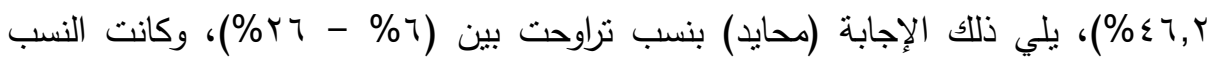
ضعيفة للإجابتين (غير موافق) و(غير موافق بشدة) كما بالجدول أعلاه.

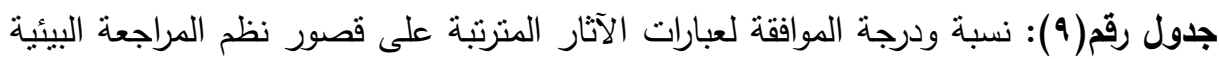
فى المنشآت الفندقية

\begin{tabular}{|c|c|c|c|c|}
\hline الموافقة & الموإقة & الإلمعياري & الوسطابي & العبارات \\
\hline 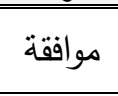 & $\Lambda \varepsilon, \wedge$ & $\cdot, \wedge 9$ & $\varepsilon, Y \varepsilon$ & ممارسات للمخاطر المنأة الفيئية الناتجة. \\
\hline 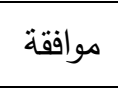 & $\vee \cdot, \wedge$ & $\cdot, 91$ & $r, 0 \leqslant$ & الإنتلاد البالتوازن للموارد البيئى نتيجة \\
\hline موافقة & $\wedge \wedge$ & $\cdot$, Or & $\varepsilon, \varepsilon$. & ألثقة للمتعاملين الإدارة البيئية تضعف \\
\hline موافقة & $\vee \vee, \Sigma$ & $\cdot, \mathrm{VV}$ & $r, \wedge r$ & تهديد التتمية السياحية المستدامة . \\
\hline موافقة & $\wedge \wedge, \varepsilon$ & •, 94 & $\varepsilon, \varepsilon r$ & والنفارات الموارد الطبيعية وزيادة التلوث \\
\hline 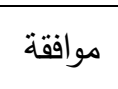 & $7 V, 7$ & $1, \cdot r$ & r, rی & للسائح • مستوى جودة الخدمة المقدمة \\
\hline 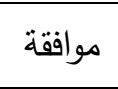 & $\varepsilon \varepsilon$ & 1,70 & $r, r$ & مثل (الايزول). \\
\hline موافقة & $T r, \Lambda$ & $1, \varepsilon r$ & $r, 1 \leq$ & توفير مصادر بديلة للطاقة . \\
\hline موافقة & $\vee q, r$ & $\cdot, \mathrm{\vee} \wedge$ & $r, 97$ & تهايد التنوع البيولوجى. \\
\hline موافقة & $\vee q, Y$ & $\cdot, T V$ & $r, 97$ & ضعف التخطيط واتخاذ القرارات. \\
\hline موافقة & $\vee \wedge$ & $\cdot, 71$ & r,q. & البيئية . نطبيق التشريعات والقوانين \\
\hline موافقة & $V \leqslant, 0$ & $\varepsilon, 99$ & \&1 & 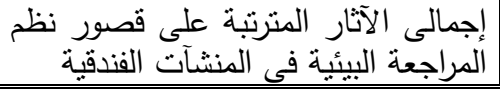 \\
\hline
\end{tabular}

من الجدول السابق للتكرارات والنسب المئوية لعبارات الآثار المنرتبة على قصور نظم

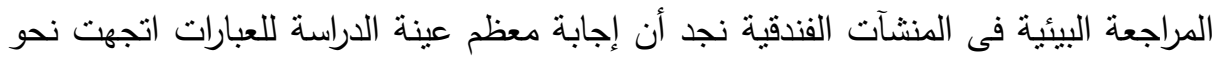

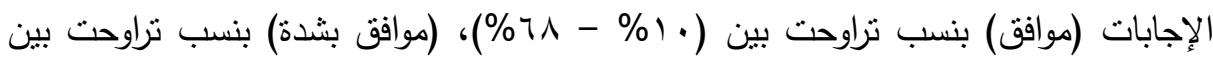

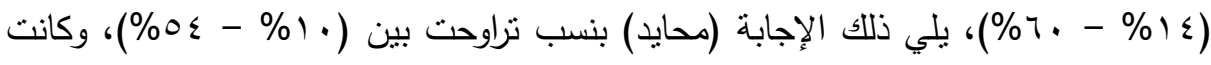


النسب ضعيفة للإجابتين (غير موافق) و (غير موافق بشدة) كما بالجدول أعلاه، بينما رفضت

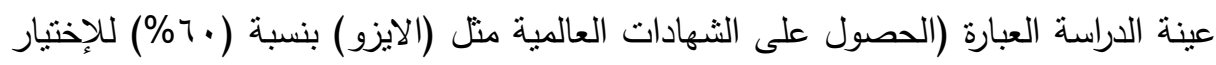
(غير موافق بشدة).

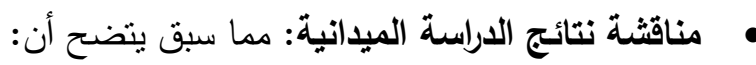
ا. هناك بعض الفنادق فئة الخمس نجوم تتطبق نظم الادارة البيئية وتقوم بنشر البيانات البيئية فى التقارير المالية. r. نظم المراجعة البيئية توفر قاعدة بيانات ملاءمة للمنشاة تستخدمها الادارة فى اتخاذ القرارات لذلك تعنبر تقارير المراجعة البيئية شكل من اشكال الرقابة الداخلية على ممارسات المنشاة ؛ مما يساعد على تحقيق التتمية السياحية المستدامة.

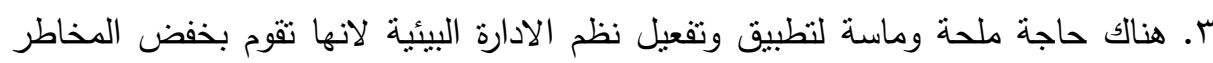
البيئية تحسن المظهر العام للمنشاة تحافظ على البيئة والموارد.

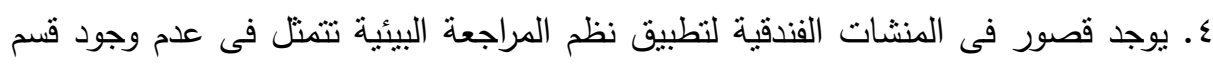

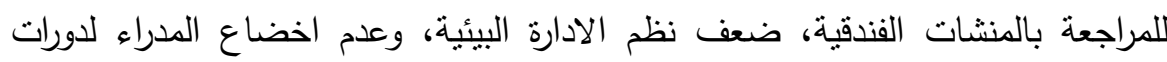
تدربية لتطوير مهاراتهم الخاص بالبيئة،ضعف التقارير البيئية.

\section{اللزوصياهت}

ا. الزام المنشآت السياحية والفندقية بنطبيق نظم الادارة البيئية.وممارسة الادارة طبقا للتشريعات والقوانين. r. الزام المنشات الفندقية والسياحية بالافصاح وقياس عن المعلومات البيئية المهمة ونشر

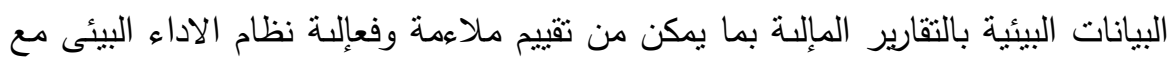
ضرورة توافر المصداقية فى المعلومات البيئية المنشورة. r. ضرورة وجود مبادىء ومعايير بيئية يعتمد علنها لاداء المراجعة البيئية مع وجود ادارة للمراجعة البيئية بالمنشات الفندقية والسياحية لتجنب الالنزامات ذات الصلة بالبيئة. 
ـ. يجب العمل على نشر الوعى البيئى فى القطاع السياحى،بعقد الندوات والمؤتمرات التى توضح أهمية المراجعة البيئية،والزام المسئولين بحضور هذه الندوات والمؤتمرات، لتحقيق

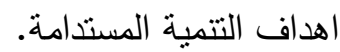

ه. يجب على الجهات المعنية وضع خطة بالمنشآت قصيرة المدى لتطبيق الممارسات الصديقة للبيئة وطويلة الاجل لتحقيق التتمية السياحية المستدامة.

\section{zall}

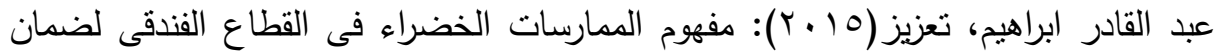

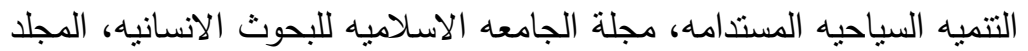
التلث والعشرون، العدد الأول. العثله

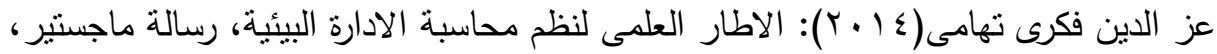
المجلة العلمية، كلية التجارة، جامعة الازهر ، العددالثامن.

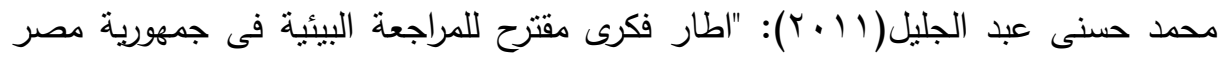

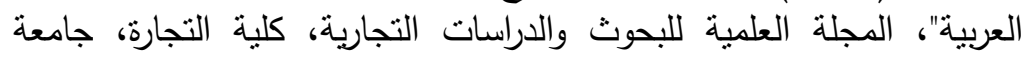

$$
\text { حلوان العدد ^. }
$$

محمد محمود عبد المجيد(Y. . . . الاتجاهات الحديثة فى المراجعة، جامعة عين شمس.

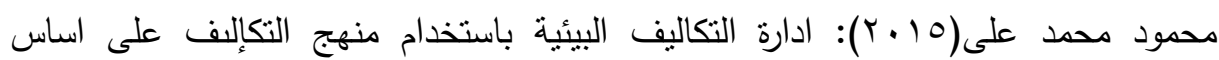

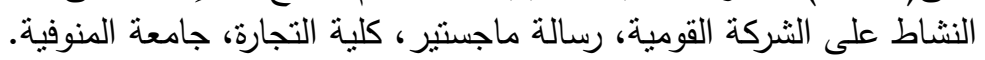

Diana,-Mihaela, Sustainable Development , Through Eco-Cultural Tourism, European Research Studies, Volume XIII, Issue (2), 2010

Georgiana Alexandru, Environmental Audit Requirement of Sustainable Development,Economics Management and Financial Markts,Vol6(1),2015

Joao Neto Simao, How Does Tourism Planning Contribute to Sustainable Development,Sust.Dev020, (2013).

$$
\text { المجلد الثالث والثالثون، الجزء الثاني، يونيو } 17 \text { ـ ب r }
$$




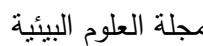

معهد الدراسات والبحوث البيئية - جامعة عين شمس لمس لمس

\title{
ACTIVATING \& DEVELOPING ENVIRONMENTAL AUDITING SYSTEMS IN TOURISM SECTOR TO ACHIEVE SUSTAINABLE DEVELOPMENT.
}

\author{
Abdel Maguid, M. M. ${ }^{(1)}$; Mohamed, Ghada, A. ${ }^{(2)}$; \\ Moustafa. K. ${ }^{(1)}$ and Elshennawy, Fify, M. $^{(3)}$
}

1) Faculty of Commerce, Ain Shams University 2) Faculty of Tourism \& Hotels, Suez Canal University. 3) Ministry of Tourism

\begin{abstract}
This paper aims basically to clarify the role of environmental auditing in improving the environmental performance for hotel and tourist facilities and mentioning its effect on the ability of the facility to comply with the environmental laws and legislations since the environmental issue and hot to preserve the environment is from the subjects having largely world concern and becoming of great importance for hotel and tourist facilities to the degree that they compete to apply the recent updates in the field of environment. The most recent update was The International Standard ISO 14001.

The environmental auditing comes to achieve the environmental control in an attempt to reduce the environmental problems and wasting natural resources resulting from deviations from the environmental plans in the hotel and tourist facilities whereas the environmental auditing includes measurement and disclosing the deviations from the environmental plans and the extent of efficiency of the environmental management systems followed within the facility and auditing environmental accounting systems. To confirm the importance of the role of the environmental auditing systems in Tourism Sector, such paper investigates social auditing as a basis for the emergence of the environmental auditing, auditing and environmental management systems in Tourism Sector. Such paper discusses the negative effects of Tourism Sector on Environment as well as shedding the light on 518

$$
\text { المجلد الثالث والثلاثثن، الجزء الثاني، يونيو } 17 \text { ـ بs }
$$
\end{abstract}


محمد محمود عبد المجيد وآخرون

sustainable tourist development. The field study depends on the questionnaire form since a field questionnaire was made and directed to Five Star Hotels existing in the outskirts of the city. The paper concluded some results related to assessment bases of environmental auditing systems for hotel facilities and the consequent results for the effect of hotel facilities on the sustainable development and the benefits of their applications as well as the results of activating and developing environmental auditing in hotel facility. At the end, the paper mentioned the consequent results arising from the lack of environmental auditing systems in Tourism Sector. 